The question of decontamination is now presenting Givaudan, Roche and the Italian government with serious problems. An Italian government commission recommended removal of topsoil to a depth of $10 \mathrm{~cm}$ in an area of 280 acres, the dismantling of all buildings in the Seveso area and the total disruption of all wildlife. These recommendations may take up to three years to implement. The sheer volume of soil to be processed and the number of buildings involved will create enormous technical problems of disposal. Great care will have to be taken to avoid further contamination by TCDD when material is removed from Seveso.

The British firm of Cremer and Warner have been retained by Givaudan to help in the task of decontamination. Cremer and Warner are chemical engineers specialising in the environmental safety aspects of industrial pollution. Data already accumulated indicate that the intensity of contamination does not conform to any uniform pattern, and the feeling is that it would be premature to implement the Italian commission's proposals, at least until potential alternatives are considered.

But no one doubts that a satisfactory policy for accident prevention and control can possibly be formulated if vital information is withheld from those whom it may affect most directly. In Seveso, the local mayors did make attempts to find out what was actually being produced at the ICMESA plant. But that was four years ago. Only last year did Givaudan finally provide some information. No mention was made of the dioxin risk, and therefore no safety measures were suggested. Even now there is conflicting information about the processes for which the ICMESA works were designed. One senior Roche executive has said the plant was producing trichlorophenol for the manufacture of the herbicide 2,4,5-T; another spokesman claimed that the plant was making trichlorophenol for the manufacture of hexachlorophene at another site.

\section{Few unaffected}

Few people have been uninvolved by the actions of the Roche subsidiary. Scientists and engineers at the Seveso plant failed to predict the extent of dioxin contamination and its spread over the countryside. Workers at the factory demanded to know of any dangers involved. Management did not inform them until two weeks after the explosion. Local residents knew nothing of the real hazards of the contamination. The medical profession, lacking an antidote, must give only symptomatic treatment. Pregnan t women, agonising over the teratogenic effects of TCDD, must decide with little firm guidance from the Church whether to undergo abortions. Ecologists cannot predict the long term effects of dioxin contamination. The authorities know that the decontamination proposals themselves are at best a mixture of policies adopted at previous accidents, leavened with a good deal of hope.

The suggestions being made now involve at the very least the implementation of strict codes of practice, to be adopted between industrial concerns and the local authorities to which they bear a great measure of responsibility. Such codes would include detailed procedures to be followed in the event of an accident. As for the withholding of information, few are accepting the obvious convenience this represents for manufacturers as a satisfactory explanation. Many are saying that with all the facts more freely available, it may, for example, be decided that the risks involved in producing trichlorophenol outweigh the necessity of a 2,4,5-T weedkiller-or a TCP mouthwash. Only the inquest now to come will reveal whether some sort of political solution is needed to ensure that the necessary information is available and to prevent a recurrence of this kind of disaster.

\title{
Europe's ageing research staffs
}

\section{Mike Duckenfield reports from Stockholm on the problem of an "unhealthy" age profile among researchers and teachers}

\section{WITH one or two exceptions,} notably Finland where spending is to be increased from $1 \%$ to $1.7 \%$ of the GNP during the next five years, research budgets in most Western European countries are having a struggle to keep pace with rising costs. Not only is government spending being cut back or slowed down, but what funds there are available are being affected by an incremental drift of salaries as young staff get older and, as in Britain and the USA, increasing unionisation. Even in Norway, where unemployment is well below $2 \%$ and economic growth at a steady $7 \%$, the prospects for those wanting research jobs are very slim.

Graduate unemployment is a problem in itself, but there is also another side to the coin: the likely prospect of universities and research institutes in most nations losing a generation of teachers and researchers during the next 15 years due to the lack of job opportunities. The problem, in short, is that the universities are now moving into the shadow of the massive expansion of higher education which took place in the 1960s. Due to this boom the average age of teachers and researchers is now very low, retirements are relatively few and future openings for new blood and ideas drastically diminished. According to academics in several countries, promotion, mobility and possibly even creativity are all likely to suffer.

The problem of an "unhealthy" age profile among researchers and teachers is beginning to be studied in nations ranging from France to Norway. Due to large scale recruitment in the middle and late $1960 \mathrm{~s}$, too large a proportion of staff are now only at the beginning of their careers. A recent Federal German survey shows that while $45.9 \%$ of professors and senior lecturers in 1966 were over 50 years old and only $22.3 \%$ under 40 , corresponding figures for 1972 were $28 \%$ and $30.5 \%$. In addition, while other teaching staff under 35 accounted for $17.4 \%$ of the total in 1966, six years later the figure was $27.3 \%$.

In Britain, too, the average age of university teachers has fallen significantly; now $63 \%$ of academic staff are under $40,26 \%$ are under 30 and $13 \%$ over 50 . In Norway $18.8 \%$ of staff are over 50 compared with $43.7 \%$ under 35, while a survey of French research workers in the Centre National de la Recherche Scientifique showed the average age of those engaged in mathematics was 28 years and 7 months and those in physics and chemistry 34 years and 5 months. In Sweden as many as two-thirds of researchers in some branches of social science are under 35.

With comparatively young staff holding most of the senior positions, future promotion prospects are well below normal. A report prepared for the Council of Europe by Gert Elstermann, academic director of the University of the Saarlands, says that the annual replacement demand for teachers in Federal German universities and colleges up to 1990 will remain much the same as it is at present in law and the social sciences. For other subjects it will stay unchanged until the mid-1980s. Similarly, in Norway prospects for the next 15 years suggest annual recruitment levels below those of any year since the early 1960s. In 
1972 there were 270 new jobs, this year only about 30 are expected.

Elstermann calculates that while an assistant lecturer in Germany had more than a $70 \%$ chance of being appointed as an established university teacher-in many cases as full professors-in the 1960s, in the 1976-85 period these chances will fall to only $15 \%$ before rising slowly to $23 \%$ in 1990 and $30 \%$ in the year 2000 . Writing in last year's annual Norwegian research review, Hans Skoie, deputy director of Norway's Science and Humanities Research Council's Institute for Studies in Research and Higher Education, commented: "There is a definite danger that universities and research establishments may develop into communities of senior citizens leaving membership of future classes of graduates with miniscule chances of getting research jobs."

$\mathrm{He}$ fears that potential scientists will be discouraged from going on to higher studies and many of the best talents lost. This in turn would lead to less research being performed through thesis work, thereby deteriorating the chances of senior staff to carry out their own projects. The trend against further studies has been evident for several years in neighbouring Sweden. In $1968,37 \%$ of graduates went on to further studies. By 1971 this had fallen to $22.5 \%$ and last year it was down to only $14 \%$. The Swedes are especially worried about their failure to attract students in mathematics and the natural sciences.

Another fear is that as the present research population gets collectively older fewer will be likely to change jobs-a trend reinforced by the tight employment market. This lack of mobility could then affect contacts between the universities, research institutes and commercial laboratories, and a Council of Europe report presented recently to a meeting of the organisation's committee for higher education and research concludes that the overall result could be stagnation and a possible decline in research creativity.

Attempts to overcome the age im- balance problem vary widely. In France priority is being given to the recruitment of contractual staff as against creating new tenured positions which would have the status and security of those of civil servants. In Federal Germany the remedy advocated has been a strict adherence to temporary contracts, with nearly all staff below professorial level being untenured, the idea being to maintain a steady flow of young academics through the universities. However, long term solutions of this kind are almost certain to be opposed by the trade unions.

Other suggestions include encouraging older researchers to apply for senior administrative posts, introducing productivity or merit increments instead of those based on seniority or simply age, making the retirement age more flexible, offering increased opportunities for leave of absence, more academic exchange programmes and, perhaps rather optimistically, simply filling staff vacancies as soon as they occur.

\section{CHEMICAL WEAPONS}

\section{Disarmament by phases}

At the Conference of the Committee on Disarmament (CCD) in Geneva, Britain last week tabled a draft convention on the prohibition and destruction of chemical weapons to complement the 1925 protocol banning their use in war. Chris Sherwell reports

THF search for a convention to cover unconventional weapons continues. The latest initiative has come from Britain in the sphere of chemical weapons, and, as the UK representative explained to the 720th plenary meeting of the $\mathrm{CCD}$, combines new ideas and constructive and realistic elements from previous drafts into a draft treaty which is being presented as a focus for negotiation.

The 17-Article draft, which the CCD's 30 member states will study before their spring session in February next year, has several features. The emphasis on "confidence building" is one. Under Article II signatories would each establish or nominate a national verification agency; in declaring whether or not they were in possession of chemical weapons and producing figures they would, it is hoped, be generating the confidence without which the main provisions of the treaty would not come into effect.

Article III is also aimed at confid- ence building. It amounts to a moratorium on production of the chemical weapons specified in a protocol still to be negotiated for Article I, by which signatories would have undertaken "never, in any circumstances, to develop, produce, or otherwise acquire, or use" chemical weapons or munitions or their delivery systems.

Another feature is the draft's threestage implementation. After the first phase, in which signatories would stop production of chemical weapons and would provide information, the main provisions of the treaty would come into operation. The third stage, marked by Article VII, provides for the phased destruction or conversion to peaceful use of chemical weapons and the destruction of stockpiles. The exact programme is left for negotiation, but a Consultative Committee would arrange for the vital aspects of verification, inspection and exchange of information. Article IX offers a framework, which could also be amplified in a protocol.

Britain does not have any specific time scale in mind for the conclusion of a chemical warfare treaty, and with the summer session of the CCD about to end, is looking only for preliminary reactions. She has shown some eye for timing, however. Eastern bloc countries put up a draft convention in March 1972, as did Japan in April
1974; non-aligned countries had suggested a series of guidelines the previous year. In 1974 Canada suggested the phased destruction of all CW agents. This received the crucial support of the USA in April this year which, in the absence of the promised US-USSR initiative, made this the appropriate time for consolidation.

The time was also right because of technological improvements in monitoring techniques and because the experience of the International Atomic Energy Agency over nuclear safeguards showed that monitoring and protection of military and commercial secrets were not mutually exclusive. The US-USSR agreement earlier this year concerning on-site inspection of "peaceful" nuclear explosions is also regarded as an important breakthrough.

Whether Britain thinks member states now really believe that chemical weapons are unnecessary or that there is no need for stockpiles is another matter; the purpose of the latest proposal, however, is not seen as being to establish which countries are thinking along these lines by discovering their reactions to the draft. A readiness to move forward is apparently perceived, although it is acknowledged that the USSR might choose to describe any concessions it makes over verification in terms of "peaceful collaboration", rather than admit the change. 